\title{
A new species of Litopeltis Hebard, 1920 from Rio de Janeiro, Brazil (Blattodea, Blaberidae, Epilamprinae) with a key to males and geographical distribution of the remaining species of the genus
}

\author{
Leonardo de Oliveira Cardoso Silva', Sonia Maria Lopes' \\ I Departamento de Entomologia, Museu Nacional, Universidade Federal do Rio de Janeiro-UFRJ \\ Corresponding author: Sonia Maria Lopes (sonialfraga@gmail.com)
}

Academic editor: G. Svenson | Received 20 March 2014 | Accepted 19 May 2014 | Published 25 June 2014

http://zoobank.org/97ED63C9-C284-4315-939C-81E439F7DF3E

Citation: Silva LOC, Lopes SM (2014) A new species of Litopeltis Hebard, 1920 from Rio de Janeiro, Brazil (Blattodea, Blaberidae, Epilamprinae) with a key to males and geographical distribution of the remaining species of the genus. ZooKeys 420: 41-49. doi: 10.3897/zookeys.420.7555

\begin{abstract}
This contribution describes a new species of Litopeltis from Brazil, L. teresopolitensis sp. n., which shows similarities with $L$. paineirensis Lopes \& Oliveira, 2010 and L. ribeiropretano Lopes \& Oliveira, 2010. It differs in characters of morphology genitalia and configuration, with the median sclerite bearing microspines on the sclerotic apex. A map showing the geographic distribution of the Brazilian species and a key to males of the other species of the genus are also presented.
\end{abstract}

\section{Keywords}

Blaberidae, key, Litopeltis, Morphology, new species, taxonomy

\section{Introduction}

The genus Litopeltis was described by Hebard (1920), based on material from Colombia. Hebard's decision to include the new genus in the subfamily Perisphaerinae 
was supported by Rehn (1928), remarking that the male of Litopeltis superficially looks much like the Epilamproid genus Leurolestes, while the brachypterous females in general resemble species of Audreia of the same subfamily. However the position of Litopeltis is in the Epilamprinae, differing from Colapteroblatta in its size and poorly defined ocelli, as well as from Mioblatta in its size, absence of tomentosity, unspotted pronotum and spiked femurs (Roth 1971). The type species is L. bispinosa (Saussure, 1893), previously included in the genus Calolampra. Currently Litopeltis includes 11 species. Lopes and Oliveira (2010) have determined that in Brazil, members of the genus are present in Rio de Janeiro, São Paulo and Mato Grosso. Beccaloni (2013) recognized 11 species for in the genus, and confirmed its presence in Central America (Costa Rica and Panama) and South America (Ecuador); and Vélez (2008) confirmed the presence of the genus in Colombia (Fig. 1). Thus, the distribution of Litopeltis comprises three Neotropical subregions: the Caribbean subregion and the western province of Ecuador (Ecuador) and Chocó (Colombia) and Andean north (Panama), together with the eastern province of Central America and west to the Isthmus of Panama (Panama and Costa Rica); the Amazon subregion, with the province of Pantanal (Mato Grosso); and the subregion of the provinces of Floresta do Paraná (São Paulo) and the Atlantic Forest (Rio de Janeiro) (Morrone 2009). Morrone stated that in the Pre-Quaternary period, the Neotropical biota expanded northward to Central America and southward to the Andean region, which could explain the dispersal of the genus to Central America and to the Amazon and Paraná subregions.

The present contribution provides information about the genus Litopeltis, including a key, and a description of a new species. The habitus, head, pronotum and external and internal genitalia with of the holotypes of the Brazilian species and new species were compared, the original descriptions were studied.

\section{Material and methods}

The genital plates were removed after dissection of the posterior part of the abdomen, using traditional dissection techniques, as described by Lopes and Oliveira (2000). After analysis, the genital plates and genital pieces were stored in microtubes containing glycerin and attached to the respective exemplar, a technique developed by Gurney et al. (1964). The terminology for the genitalia and the taxonomic classification follow Roth (2003). The specimens were compared with other specimens of Litopeltis deposited in the Blattodea Collection of the Museu Nacional of Rio de Janeiro (MNRJ), and with descriptions in the literature. Digital images of the habitus, pronotum, head and genitalia were taken with a camera mounted on a stereoscope. The holotype is deposited in the collection of the Department of Entomology at the Museu Nacional of Rio de Janeiro (MNRJ). The text was translated by Prof. Solange Garrido and edited by Dr. Janet W. Reid. The map was taken from MAPA DA AMERICA (http://www.mapadaamerica.com/) (Fig. 1). 

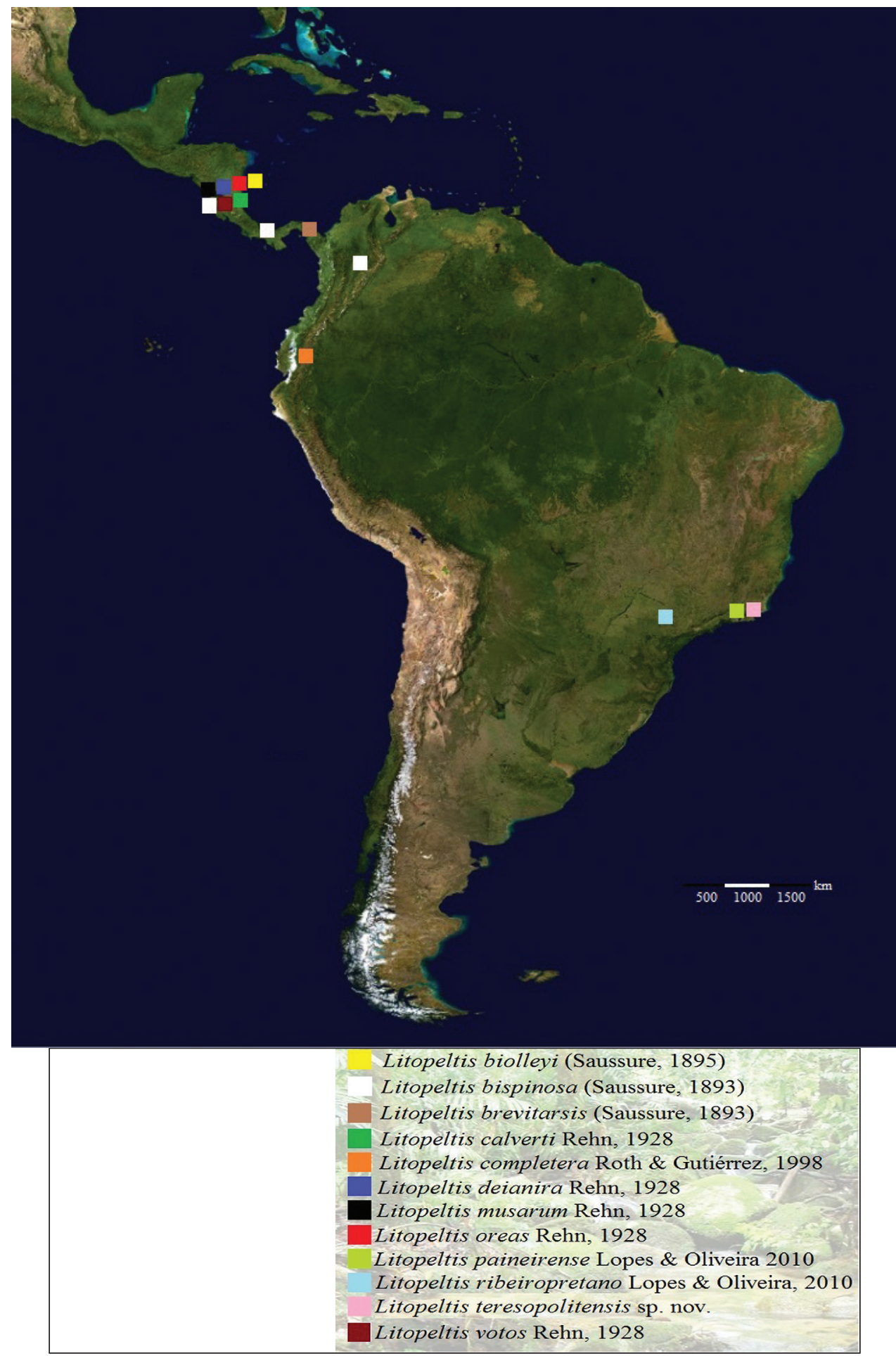

Figure I. Map of geographical distribution of Litopeltis Hebard, 1920. 


\section{Results}

\section{Litopeltis teresopolitensis $\mathbf{s p} . \mathbf{n}$.} http://zoobank.org/6B0F173A-D1F4-439E-BBF1-90387F3DDBBC Figs 2-9

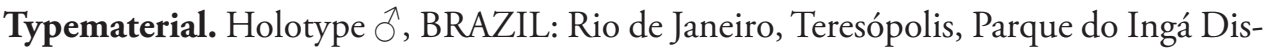
trict, III/2013, Schilithz, A. G. col.

Etymology. The name is given for Teresópolis, the collection locality of the holotype.

Description. Dimensions (mm): Male holotype, total length: 20.7; length of pronotum: 4.0; width of pronotum: 4.5; length of tegmen: 17.5; width of tegmen: 4.4.

Male holotype. Coloration. General coloring chestnut (Fig. 2). Head with dark eyes, vertex dark with a white vertical line and interocular space in center of the forehead and center of clypeus black (Fig. 3); antennae opaque, first 26 antennomeres glossy, remainder tomentose. Central disk of pronotum with black spots (Fig. 4). Legs with bases of coxae black, spines on tibiaes, dorsal part of tarsus and claws brown, remaining segments of legs, pulvilli and arolium white. Tegmen hyaline, wings with brown veins. Abdomen with dark-brown segments and whitish-yellow lateral margins.

Head. Vertex hidden; interocular space ample, subequal to distance between bases of antennal insertions. Antennae tomentose distally, reaching slightly over half of length of abdomen. Ocelli developed. Maxillar palpi tomentose.

Thorax. Pronotum transverse, trapezoid, convex with rounded apex and slightly sinuous base. Legs short and robust. Femur I, anteroventral margin bearing three spines in basal half, a row of 21 spines and one longer apical spine in apical half, with a large robust spine on apex; posteroventral margin with row of seven slender spines, ending with two robust spines in apical third. Femur II, anteroventral margin bearing two robust spines, one median, the other apical; posteroventral margin with three to four robust spines. Femur III, antero- and posteroventral margin with two to three robust spines. Large pulvilli present on all tarsomeres; arolia present; claws symmetrical with slight specialization, having eight small rectangular structures.

Wings. Tegmina long, overreaching apex of cerci; marginal field concave and well delineated; scapular field long and narrow with apically oblique arrangement of veins; discoidal field ample and convex, apically widened with a longitudinal arrangement of veins; anal field ample, elongated, with three axillary veins. Hind wings with costal sector having the apices of the veins dilated; apical triangle present; anal field folded fanwise.

Abdomen. Absence of tergal modifications. Supra-anal plate short and wide, with smooth median apical indentation; cerci short (Fig. 5). Subgenital plate widened and prominent medially, with acute styli in median apical region of plate (Fig. 6). Left phallomere with median sclerotic structure in shape of an inverted "V" (Fig. 7); median sclerite developed, with microspines on sclerotized apex (Fig. 8); right phallomere hook-shaped (Fig. 9).

Diagnosis. This species appears to be to L. paineirensis Lopes \& Oliveira, 2010 (Figs 10-17), which it resembles in the median sclerite (Fig. 16) and the subgenital plate (Fig. 14); and to L. ribeiropretano Lopes \& Oliveira, 2010 (Figs 18-25), which has a similar right phallomere (Fig. 25). 


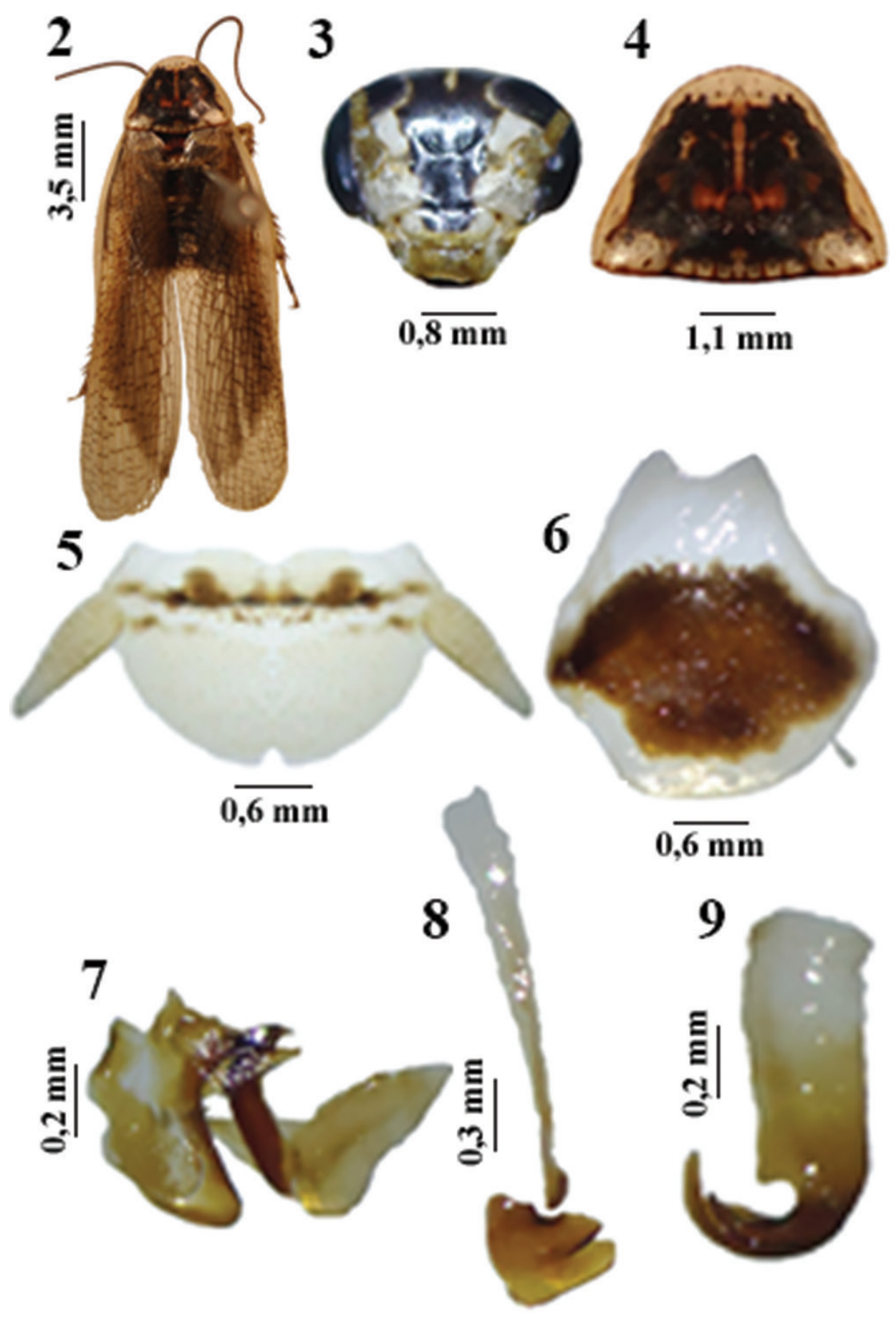

Figures 2-9. Litopeltis teresopolitensis sp. n., male $\mathbf{2}$ habitus (dorsal view) $\mathbf{3}$ head (ventral view) $\mathbf{4}$ pronotum (dorsal view) $\mathbf{5}$ supra-anal plate (dorsal view) $\mathbf{6}$ subgenital plate (ventral view) $\mathbf{7}$ left phallomere (dorsal view) 8 median sclerite (dorsal view) $\mathbf{9}$ right phallomere (dorsal view). 

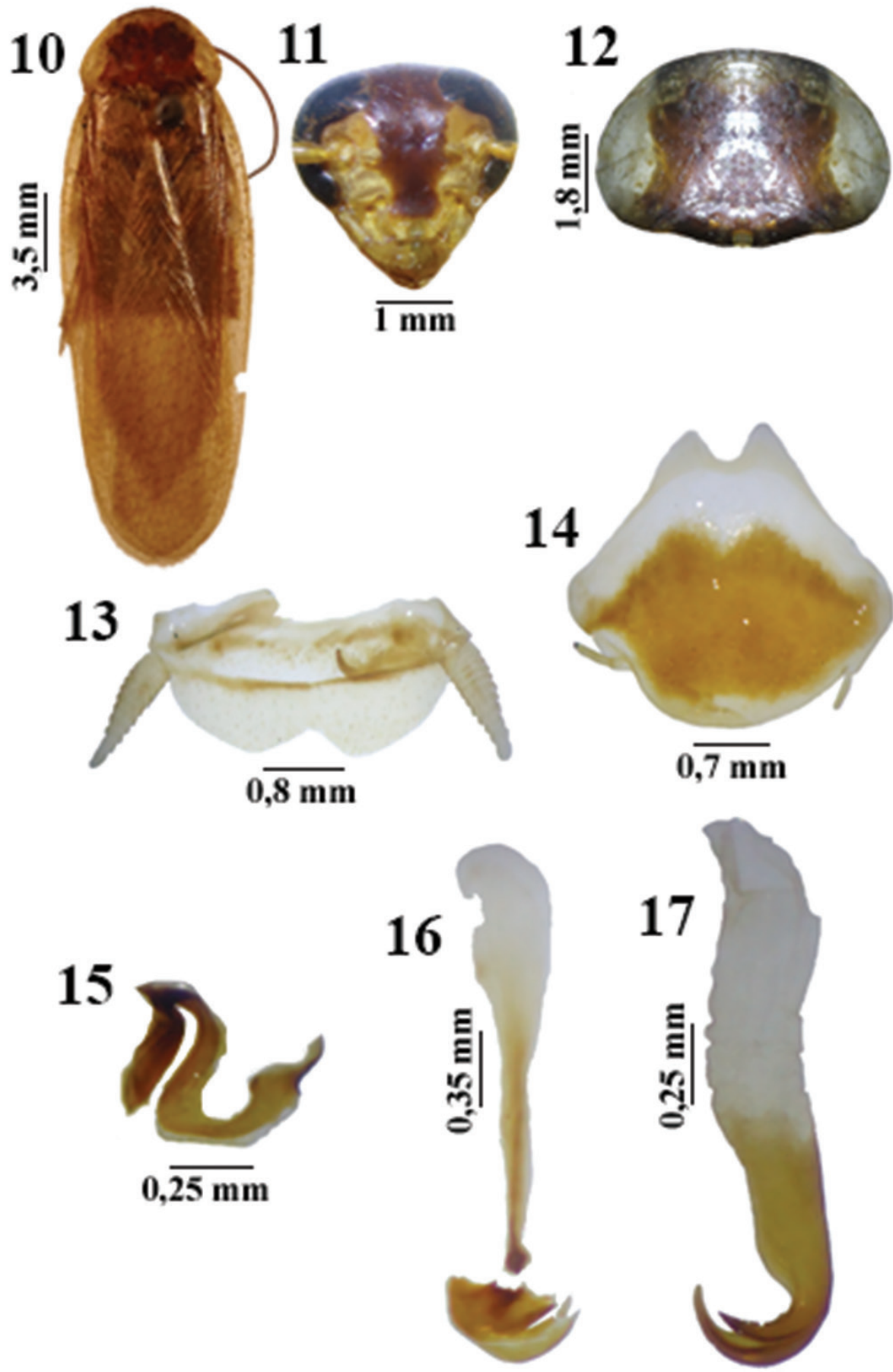

Figures I0-I 7. Litopeltis paineirensis Lopes \& Oliveira, 2010, male. $\mathbf{I 0}$ habitus (dorsal view) II head (ventral view) $\mathbf{2}$ Pronotum (dorsal view) I $\mathbf{3}$ supra-anal plate (dorsal view) I4 subgenital plate (ventral view) $\mathbf{5}$ left phallomere (dorsal view) $\mathbf{1 6}$ median sclerite (dorsal view) 17 right phallomere (dorsal view) 

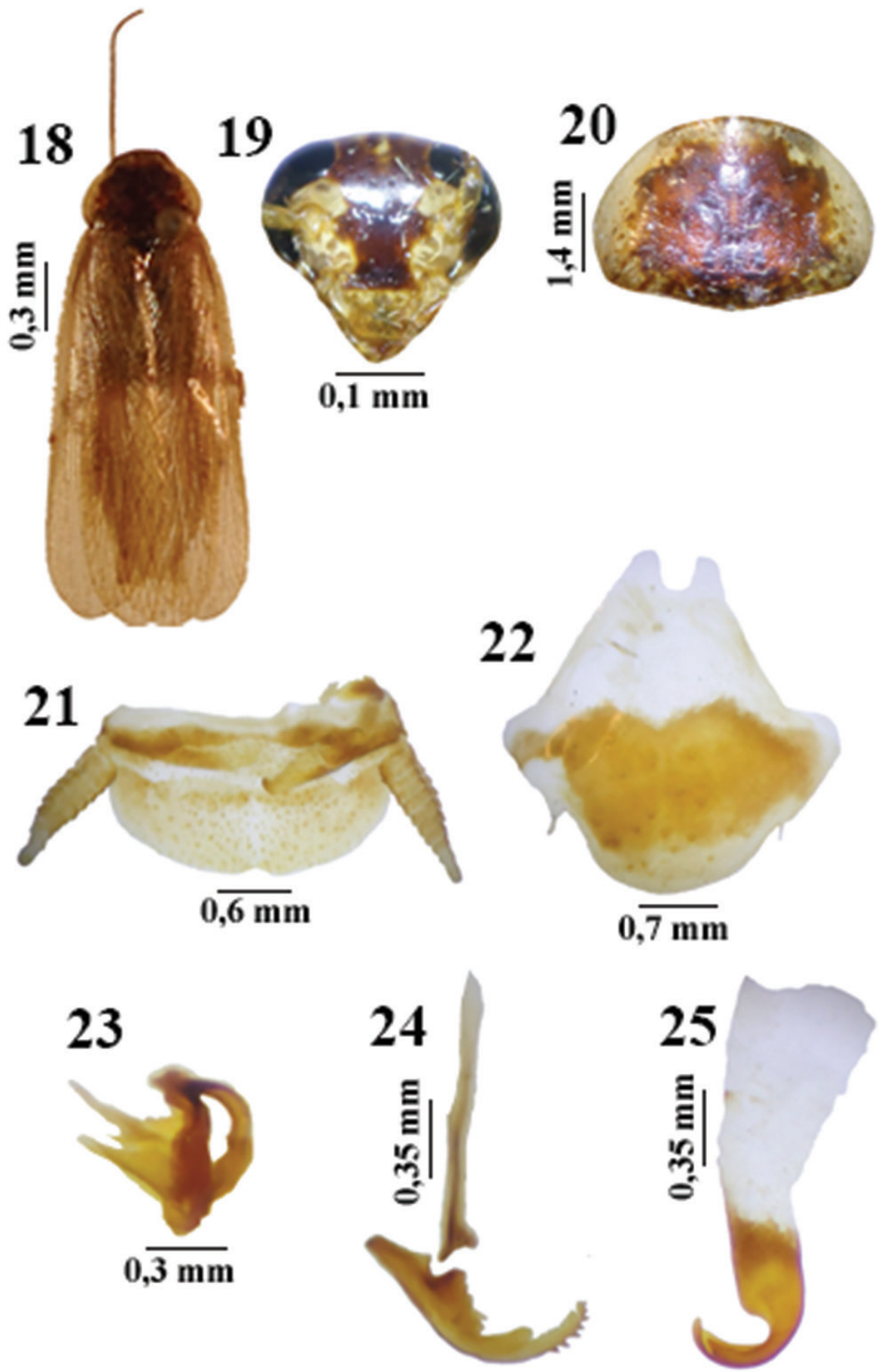

Figures 18-25. Litopeltis ribeiropretano Lopes \& Oliveira, 2010, male. 18 habitus (dorsal view) 19 head (ventral view) $\mathbf{2 0}$ pronotum (dorsal view) $\mathbf{2} \mathbf{I}$ supra-anal plate (dorsal view) $\mathbf{2 2}$ subgenital plate (ventral view) $\mathbf{2 3}$ left phallomere (dorsal view) $\mathbf{2 4}$ median sclerite (dorsal view) $\mathbf{2 5}$ right phallomere (dorsal view) 


\section{Key to adult males of the genus Litopeltis}

The species L. brevitarsis (Saussure, 1893), L. compleptera Roth \& Gutierrez, 1998 and L. musarum Rehn, 1928 were not included in the key because they were described from females.

Neotropical species endemic to Brazil

Central disk with nonuniforme spots on pronotum; apex of median sclerite without spike like protuberances (Figs 4, 8, 12 and 16)

- $\quad$ Central disk with uniforme spots on pronotum; apex of median sclerite with spike-like protuberances (Figs 20 and 24) . L. ribeiropretano Right phallomere abruptly tapering pre-apically (Fig. 9) ...L. teresopolitensis sp. n. Right phallomere only slightly tapering pre-apically (Fig. 17) ....L. paineirensis

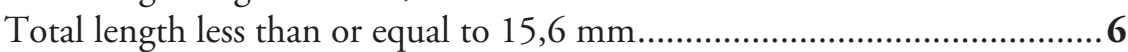

Dorsal sclerite from median sclerite rounded in the apex and developed, almost reaching the prepuce extension

L. bispinosa (Saussure, 1893) (Figs 39a-41 in Roth 1971)

- $\quad$ Dorsal sclerite from median sclerite, reduced and thin in the apex, not reaching all prepuce extension

L. biolleyi (Saussure, 1895) (Figs 42-44 in Roth 1971)

6 Dorsal sclerite from median sclerite foliaceous, not reaching the middle of prepuce. L. oreas Rehn, 1928 (Figs 45-47 in Roth 1971)

- $\quad$ Dorsal sclerite from median sclerite not foliaceous

$7 \quad$ Length of pronotum less than or equal to $4,8 \mathrm{~mm}$ L. votos Rehn, 1928

- $\quad$ Length of pronotum longer than $4,8 \mathrm{~mm}$ 8

\section{References}

Beccaloni GW (2013) Blattodea Species File Online. Version 5.0/5.0. World wide web electronic publication. http://Blattodea.SpeciesFile.org [accessed in November 2013]

Google Earth (2013) Google Earth for Windows. Version 7.1.1.1888. Google Inc., Mountain View. Gurney AB, JP Kramer, Steyskal GC (1964) Some Techniques for the Preparation, Study and

Storage in Microvials of Insect Genitalia. Annals of the Entomological Society of America 57: 240-242.

Hebard M (1920) The Blattidae of Panama. Memoirs of the American Entomological Society, Philadelphia 4: 1-148.

Lopes SM, Oliveira EH (2010) Novo registro para Litopeltis Hebard, 1920 no Brasil e descrição de duas espécies novas (Blaberidae, Epilamprinae). Biota Neotropical 2(10): 85-89. 
Morrone JJ (2009) Evolutionary Biogeography: An Integrative Approach with Case Studies. Columbia University Press, New York, 301pp.

Rehn JAG (1928) New or little known Neotropical Blattidae (Orthoptera). Number One. Transactions of the American Entomological Society 54: 125-194.

Roth LM (1971) The male genitalia of Blattaria. V. Epilampra spp. (Blaberidae: Epilamprinae). Psyche 77: 436-486. doi: 10.1155/1970/46805

Roth LM (1971) The male genitalia of Blattaria. VII. Galiblatta, Dryadoblatta, Parcoblatta, Colapteroblatta, Nauclidas, Notolampra, Litopeltis and Caricasia (Blaberidae: Epilamprinae). Psyche 8: 180-192. doi: 10.1155/1971/21805

Roth LM (2003) Systematics and phylogeny of cockroaches (Dictyoptera: Blattaria). Oriental Insects 37: 1-186. doi: 10.1080/00305316.2003.10417344

Vélez A (2008) Checklist of Colombian cockroaches (Dictyoptera, Blattaria). Biota Colombiana 9(1): 21-38. 